This is the post-print version of the article J. Yao, M.F. Pantano, N.M. Pugno, C.W.M. Bastiaansen, T. Pejis. High-performance electrospun co-polymide nanofibers. Polymer. 76:105-112, 2015.

The Publisher's version is available at http://dx.doi.org/10.1016/j.polymer.2015.08.053

\title{
High-performance electrospun co-polyimide nanofibers
}

\author{
Jian Yao $^{\text {a }}$, Maria F. Pantano ${ }^{\text {b }}$, Nicola M. Pugno ${ }^{\text {a, b, e }}$, Cees W.M. Bastiaansen ${ }^{\text {a, c }}$, Ton Peijs ${ }^{\text {a, d, }}$ * \\ ${ }^{\text {a }}$ School of Engineering and Materials Science, Materials Research Institute, Queen Mary University of London, Mile \\ End Road, London E1 4NS, UK \\ b Laboratory of Bio-Inspired and Graphene Nanomechanics, Department of Civil, Environmental and Mechanical \\ Engineering, University of Trento, Via \\ Mesiano 77, 38123 Trento, Italy \\ ${ }^{\mathrm{c}}$ Faculty of Chemistry and Chemical Engineering, Eindhoven University of Technology, P.O. Box 513, 5600 MB, \\ Eindhoven, The Netherlands \\ ${ }^{\mathrm{d}}$ Nanoforce Technology Ltd., Joseph Priestly Building, Queen Mary University of London, Mile End Road, London E1 \\ $4 \mathrm{NS}, \mathrm{UK}$ \\ ${ }^{\mathrm{e}}$ Centre for Materials and Microsystems, Fondazione Bruno Kessler, Trento, Italy
}

* Corresponding author. School of Engineering and Materials Science, Materials Research Institute, Queen Mary University of London, Mile End Road, London E14NS, UK. Tel.: p44 (0) 2078828865. E-mail addresses: j.yao@qmul.ac.uk (J. Yao), t.peijs@qmul.ac.uk (T. Peijs).

Abstract. Co-polyimide nanofiber based on BPDA (3, 30, 4, 40-Biphenyltetracarboxylic dianhydride)/PDA (p-Phenylene-diamine)/ODA (4, 40-Oxydianiline) (BPO) were produced by electrospinning followed by imidization from precursor polyamic acid (PAA) nanofiber. The aligned co-polyimide nanofiber mats possessed a modulus, strength and strain-at-break of respective $10 \mathrm{GPa}, 1.04 \mathrm{GPa}$, and $13.5 \%$. In comparison with previously reported co-polyimide nanofibers BPDA/BPA/ODA (BBO) with similar chemical structures, these BPO co-polyimide nanofibers can be as stiff and strong while at the same time exhibiting moderate ductility. On the other hand, the current BPO co-polyimide nanofibers exhibited a greater toughness than previously reported homo-polyimide (BPDA/PDA) nanofibers due to their relatively high strain-at-break, leading to similar levels of toughness as Kevlar fibers. A novel and efficient way to evaluate mechanical properties of aligned nanofiber bundles ( 30 nanofibers in a bundle) by virtue of a micro-tensile tester was also reported. Young's modulus of $38 \pm 2 \mathrm{GPa}$ and tensile strength of 1550 $\pm 70 \mathrm{MPa}$ were found for nanofiber bundles and were significantly higher than those of aligned mats, and are among the highest reported for electrospun fibers. Further evaluation of this bundle data using Daniel's theory based on Weibull statistics resulted in a predicted tensile strength of single copolyimide nanofibers of about $1.9 \mathrm{GPa}$.

Keywords. Electrospinning, Co-polyimide nanofibers, Mechanical properties

\section{Introduction}

Over the last two decades, electrospinning has attracted great interests as it provides a viable and simple method to create ultrafine continuous nanofibers [1-3]. Despite the potential utilization of electrospun nanofibers in many fields, their success has been limited so far due to their poor mechanical properties compared to those of fibers made by conventional processes such as melt- or solution spinning [4-9]. The main reason for this is the competition between flow-induced chain orientation and chain relaxation before fiber solidification, leading to low degrees of molecular orientation in as-spun fibers based on flexible chain polymer fibers [5]. It is for this reason that high performance fibers based on flexible chain polymers are typically post-drawn in the solid state below their melting temperature, where relaxation times are nearly infinite. However, such an approach is usually not feasible in electrospinning due to technological difficulties with respect to the post-drawing of nano-sized fibers [10]. Only limited stretching or drawing has been attempted 
This is the post-print version of the article J. Yao, M.F. Pantano, N.M. Pugno, C.W.M. Bastiaansen, T. Pejis. High-performance electrospun co-polymide nanofibers. Polymer. 76:105-112, 2015.

The Publisher's version is available at http://dx.doi.org/10.1016/j.polymer.2015.08.053

to oriented nanofiber mats in order to induce some levels of molecular orientation and crystallinity, which often remain rather low [11,12].

Although some evidence exists of confinement induced molecular orientation in the case of ultrafine nanofibers, the orientation and particularly chain extension achieved in electrospun fibers based on flexible chain polymers is often rather limited, leading to only moderate improvements in Young's modulus (typically 2-4 times bulk polymer) [13-15], well below those attainable in commercial melt- or solution spun fibers (typically 10-100 times bulk polymer) [5].

As the introduction of a post-drawing step in commercial electrospinning processes may prove technologically challenging, the use of rigid-rod polymers as an alternative to flexible chain polymers may be more promising as here chain extension has already been built in and chains can be readily oriented during spinning. p-Aramid fiber is the prime example of a high performance synthetic fibers spun from rigid (or semi-rigid) polymer chains. Great success has been achieved by developing through these routes high performance p-aramid fibers like Kevlar® and Twaron® with typical fiber diameters of around $14 \mathrm{~mm}$ [16-18]. However, until recently few efforts were devoted to the development of electrospun p-aramid nanofibers. Our recent paper reported the electrospinning of $19.4 \mathrm{wt} \%$ of PPTA solution which is the required concentration for producing high performance p-aramid fibers [19]. It is found that the Young's modulus and tensile strength of obtained fibers increased with the decreasing fiber diameter. The thinnest fiber (2.1um) tested shows the highest mechanical properties with values of tensile strength and Young's modulus of 1.1 $\mathrm{GPa}$ and $59 \mathrm{GPa}$, respectively. However, the electrospinning process reported was not performed in a good manner and only small quantities of electrospun p-aramid fiber could be collected.

An alternative method to produce high performance nanofibers is by using soluble flexible chain polyimide (PI) precursors for electrospinning and subsequently converting these into chain extended polyimide structures through a chemical fiber imidization step. Polyimides are normally not soluble in common organic solvent because of their high chain rigidity hence electrospinning the corresponding polyamic acid solution followed by imidizing these polyamic acid precursor fibers is a potential route to produce polyimide nanofibers. Huang et al. electrospun well-aligned poly(pphenylenebiphenyl tetracarboxamide) (BP-PAA) nanofibers and then imidized these homopolymers into BPDA/PDA nanofibers [10]. The Young's modulus, tensile strength and elongation at break of their well-aligned BPDA/PDA nanofiber mat were about $15 \mathrm{GPa}, 660 \mathrm{MPa}$ and $4.9 \%$, respectively. Enhancement of mechanical properties compared to the BP-PAA precursor nanofibers (Young's modulus of $2.1 \mathrm{GPa}$, tensile strength of $187 \mathrm{MPa}$ and elongation at break of $10.3 \%$ ) is due to an imidization process where the flexible BP-PAA chains are transformed into rigid-rod molecular chains of BPDA/PDA which become oriented and extended along the fiber axis. Co-polyimides are also suitable for producing nanofibers by using BPDA/BPA/ODA (composition mole ratio can be found in Table 1). Nanofibers with Young's moduli of $6 \mathrm{GPa}$, tensile strengths of $980 \mathrm{MPa}$ and an elongation at break of $22.2 \%$ were obtained and the resulting nanofibers had greater toughness compared to the homo-polyimide nanofibers but at the expense of stiffness [20].

Table 1. Mechanical properties of three different types of electrospun polyimide nanofiber aligned mats $[10,20]$.

\begin{tabular}{|l|l|l|l|}
\hline Material (mole ratio) & $\begin{array}{l}\text { Young's modulus } \\
(\mathrm{GPa})\end{array}$ & $\begin{array}{l}\text { Tensile strength } \\
(\mathrm{MPa})\end{array}$ & Strain (\%) \\
\hline BPDA/PDA/ODA $(2: 1: 1)$ (this work) & 10 & 1040 & 13.5 \\
\hline BPDA/BPA/ODA $(2: 1: 1)$ & 6.3 & 983 & $22.2[20]$ \\
\hline BPDA/PDA $(1: 1)$ & 15 & 660 & $4.97[10]$ \\
\hline
\end{tabular}

The focus of this paper is to develop an electrospun copolyimide nanofiber with greater stiffness than reported BBO copolyimide nanofibers and higher tensile strength than the reported BPDA/PDA nanofibers with the aim of using these fibers as reinforcements for high performance 
This is the post-print version of the article J. Yao, M.F. Pantano, N.M. Pugno, C.W.M. Bastiaansen, T. Pejis. High-performance electrospun co-polymide nanofibers. Polymer. 76:105-112, 2015.

The Publisher's version is available at http://dx.doi.org/10.1016/j.polymer.2015.08.053

nanocomposites. For this, attempts were made to introduce the flexible moiety ODA into the rigid homo-polyimide structure of BPDA/PDA. Its corresponding polyamic acid was synthesized and electrospun into aligned nanofiber mats and then imidized to BPO co-polyimide nanofibers. Both the PAA nanofibers and BPO nanofibers were characterized by means of SEM, FTIR, and XRD. Mechanical properties of both BPO nanofiber aligned mats (or UD mats) and aligned nanofiber bundles were evaluated. Finally, the tensile strength of a single BPO nanofiber was estimated from the bundle data by applying Daniel's theory based on Weibull statistics.

\section{Experimental}

\subsection{Materials}

3, 30, 4, 40-Biphenyltetracarboxylic dianhydride (BPDA), 4, 4'-oxydianiline (ODA) and pPhenylenediamine (PDA) were purchased from Sigma-Aldrich. N, N-Dimethylformamide (DMF, $99.8 \%$, anhydrous) was supplied by Sigma-Aldrich. All materials were used without further purification.

\subsection{Synthesis of co-polyimide BPDA/PDA/ODA polyamic acid}

$2.942 \mathrm{~g}(0.01 \mathrm{~mol})$ BPDA, $0.545 \mathrm{~g}(0.005 \mathrm{~mol})$ PDA and $1.001 \mathrm{~g}(0.005 \mathrm{~mol})$ ODA were mixed together in $40.400 \mathrm{~g}$ of DMF within a three-neck flask which was ventilated with dry nitrogen gas. Intense stirring was applied in the polycondensation process at low temperature $\left(0{ }^{\circ} \mathrm{C}\right)$ for $20 \mathrm{~h}$. A $10 \mathrm{wt} \%$ solution of the polyamic acid product in DMF was obtained eventually.

\subsection{Electrospinning of BPDA/PDA/ODA polyamic acid}

The $10 \mathrm{wt} \%$ solution synthesized above was diluted to $4.5 \mathrm{wt} \%$ by adding anhydrous DMF to get a homogenous spinning solution. Then the spinning solution was placed inside a syringe and pumped through a metallic needle acting as one electrode at a controlled flow rate of $0.5 \mathrm{ml} / \mathrm{h}$. A voltage of $25 \mathrm{kV}$ was applied to the needle of which then a solution jet was ejected and collected on a rotating drum with a speed of $2200 \mathrm{rpm}$ wrapped with aluminum foil acting as the ground electrode. Evaporation of solvent and stretching of solution jet occurred and solid nanofibers were collected on the surface of the drum. The nanofiber mat could be easily peeled off from the aluminum foil and was dried in a vacuum oven at $70{ }^{\circ} \mathrm{C}$ for $3 \mathrm{~h}$ to remove all residual solvent.

\subsection{Conversion from BPDA/PDA/ODA polyamic acid to polyimide}

To obtain BPDA/PDA/ODA polyimide from its precursor fibers, these as-spun nanofibers were heated in a nitrogen atmosphere using the following procedure:

(1) Heating up to $240{ }^{\circ} \mathrm{C}$ at a rate of $10{ }^{\circ} \mathrm{C} / \mathrm{min}$ and annealing for $2 \mathrm{~h}$

(2) Heating up to $380{ }^{\circ} \mathrm{C}$ at a rate of $1.5^{\circ} \mathrm{C} / \mathrm{min}$ and annealing for $1 \mathrm{~h}$

(3) Cooling down to room temperature.

\subsection{Characterization}

The UD nanofiber mat was cut into rectangular strips with a width of $4 \mathrm{~mm}$ and length of $50 \mathrm{~mm}$. Mechanical tests of nanofiber mats were performed using an Instron 5566 universal testing machine with a load cell of $100 \mathrm{~N}$. Each sample was griped directly in the clamps with the gauge length being determined by the distance between the two clamps. The thickness of pure solid nanofiber strip (without consideration of voids between nanofibers) is determined using Equation (1). 
This is the post-print version of the article J. Yao, M.F. Pantano, N.M. Pugno, C.W.M. Bastiaansen, T. Pejis. High-performance electrospun co-polymide nanofibers. Polymer. 76:105-112, 2015.

The Publisher's version is available at http://dx.doi.org/10.1016/j.polymer.2015.08.053

$\mathrm{T}_{\mathrm{f}}=\mathrm{W}_{\mathrm{f}} / \mathrm{DL}_{\rho \mathrm{f}}$

where $\mathrm{W}_{\mathrm{f}}, \mathrm{D}$ and $\mathrm{L}$ represent the weight, width and length of PI nanofiber strip respectively. $\rho f$ is the density of solid PI nanofibers without air which is measured to be $1.48 \mathrm{~g} / \mathrm{cm}^{3}$ (the density of PAA nanofibers is $1.25 \mathrm{~g} / \mathrm{cm} 3$ ) using a gas pycnometer (AccuPyc $1330 \mathrm{He}$, U.S.A.).

It should be noted that measuring the thickness of nanofiber strips using a micrometer is not accurate as the numerous voids between individual nanofibers are included, which could lead to 4-5 times thicker than the actual thickness of strips. It is for this reason that in this report the thickness of all of the samples was determined by calculation based on their actual volume exclusive of the volume of voids between nanofibers.

Nanofiber bundles containing 30 filaments were prepared by carefully removing them from the UD-mat using a sharp tweezer and then glued on $1 \mathrm{~mm} \times 1 \mathrm{~mm}$ paper frames. As a micro-tensile tester, an Agilent T150 with a maximum load of $500 \mathrm{mN}$ and load resolution of $50 \mathrm{nN}$ was applied to test the mechanical properties of the nanofiber bundles. Every series of samples was measured five times. Samples which failed close to or inside the grips were discarded. The surface morphology of the nanofibers was investigated using a scanning electron microscope (Jeol JSM6300F). All samples were gold-coated before observation. 2D wide-angle X-ray diffraction (WAXD) patterns were recorded using an APEX II detector in transmission mode with $\mathrm{Cu} \mathrm{Ka}$ radiation from the Incoatec microfocus source. Diffraction patterns were collected with $30 \mathrm{~s}$ exposure and calibrated with an $\mathrm{A} 12 \mathrm{O} 3$ filled capillary.

\section{Results and discussion}

\subsection{Synthesis of BPO polyamic acid}

The polycondensation process (Fig. 1) of monomers BPDA, PDA and ODA with a mole ratio of $2: 1: 1$ in organic solvent is effective and rapid. Hence, the synthesis should be performed at low temperatures $\left(0{ }^{\circ} \mathrm{C}\right)$ to inhibit side reactions. A $10 \mathrm{wt} \%$ solution of polyamic acid in DMF was obtained after $20 \mathrm{~h}$.

\subsection{Electrospinning of polyamic acid, imidization process and characterization}

In order to create nanofiber reinforced composites with good mechanical properties it is vital to produce high performance electrospun nanofiber mats which are well aligned along one direction as nanofiber misalignment will significantly reduce the mechanical properties of such mats [10,21]. In this study, a high speed rotating disc (diameter of $10 \mathrm{~cm}$ ) with a speed of $2200 \mathrm{rpm}$ was used to collect the nanofibers. It should be also mentioned that the morphology of the nanofibers plays an important role in their final mechanical properties. Beaded and non-uniform nanofibers should be avoided by optimizing the spinning solution (conductivity, concentration, etc.) and spinning parameters (applied voltages, spinning distance, temperature, rotating speed of collector, etc.). Fig. 2a shows a representative morphology of an aligned polyamic acid (PAA) nanofiber mat electrospun from $4.5 \mathrm{wt} \%$ spinning solution, as prepared by diluting the $10 \mathrm{wt} \%$ polyamic acid solution with DMF. Electrospinning of lower polymer concentrations would lead to beaded fibers whilst higher concentrations result in bigger fibers or a solution that is too viscous to spin. The electrospun polyamic acid nanofibers produced from the well prepared PAA solution were reasonably well-aligned, uniform and smooth. They possess diameters ranging from $180 \mathrm{~nm}$ to 300 $\mathrm{nm}$ with the majority of the nanofibers having a diameter of around $275 \mathrm{~nm}$. 
This is the post-print version of the article J. Yao, M.F. Pantano, N.M. Pugno, C.W.M. Bastiaansen, T. Pejis. High-performance electrospun co-polymide nanofibers. Polymer. 76:105-112, 2015.

The Publisher's version is available at http://dx.doi.org/10.1016/j.polymer.2015.08.053

\section{Synthesis of BPO polyamic acid}<smiles>O=C1OC(=O)c2cc(-c3ccc4c(c3)C(O)OC4O)ccc21</smiles>

BPDA<smiles>Nc1ccc(N)cc1</smiles>

PDA

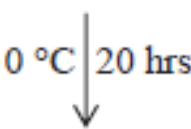<smiles>Nc1ccc(Oc2ccc(N)cc2)cc1</smiles>

ODA<smiles>Cc1ccc(Oc2ccc(NC(=O)c3cc(-c4ccc(C(=O)O)c(C(=O)Nc5ccc(C(C)(C)C)c(C(=O)Nc6ccc(C(=O)O)c(C(=O)NC7CCCCC7)c6)c5)c4)ccc3C(=O)O)cc2)cc1</smiles>

BPDA/PDA/ODA polyamic acid

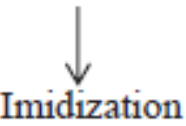<smiles>C=C(c1ccc(N2C(=O)c3ccc(-c4ccc5c(c4)C(=O)N(C(C)(C)C)C5=O)cc3C2=O)cc1)N1C(=O)c2ccc(-c3ccc4c(c3)C(=O)N(c3ccc(Oc5ccc(C)cc5)cc3)C4=O)cc2C1=O</smiles>

BPDA/PDA/ODA co-polyimide

Fig. 1. Low temperature polycondensation and imidization process.

(a)

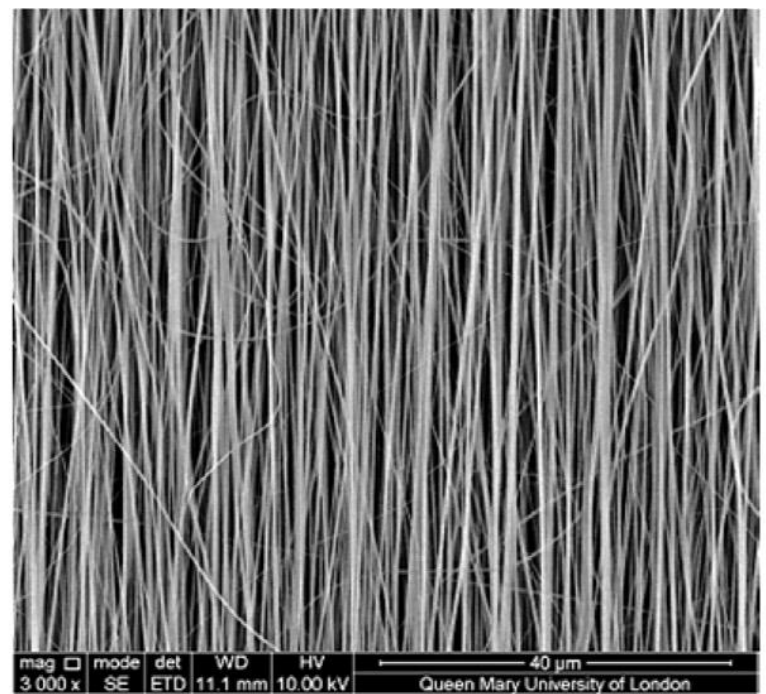

(b)

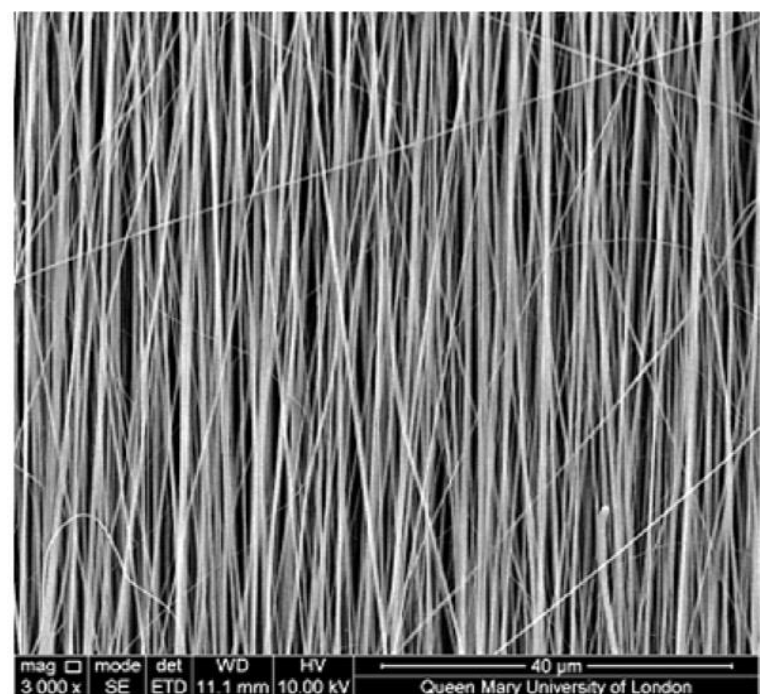

Fig. 2. SEM micrographs of (a) polyamic acid nanofibers before imidization; (b) co-polyimide nanofibers after imidization. 
This is the post-print version of the article J. Yao, M.F. Pantano, N.M. Pugno, C.W.M. Bastiaansen, T. Pejis. High-performance electrospun co-polymide nanofibers. Polymer. 76:105-112, 2015.

The Publisher's version is available at http://dx.doi.org/10.1016/j.polymer.2015.08.053

Before imidization, the polyamic acid (PAA) nanofibers needed to be dried in a vacuum oven to avoid fiber fusion during the following imidization step [4]. Next, the solvent-free PAA nanofiber mat was imidized at elevated temperatures (see experimental procedure) to induce chain extension. Fig. $2 b$ shows that there are no obvious differences in fiber orientation in the nanofiber mats before and after imidization.

FTIR was used to study the imidization process. The most obvious difference in the FTIR spectrums as shown in Fig. 3 is the disappearance of the broad absorption peak in the range of $2900-3600 \mathrm{~cm}^{-1}$ after imidization, which is attributed to stretching vibration of carboxyl groups and amide groups of polyamic acid. Also, the peak at $1370 \mathrm{~cm}^{-1}$ which is attributed to the stretching vibration of $-\mathrm{C}-\mathrm{N}$ - in imide cycle and both the peaks at $1776 \mathrm{~cm}^{-1}$ and $1720 \mathrm{~cm}^{-1}$ are indication of stretching vibration of $\mathrm{C}=\mathrm{O}$ in the imide cycle. All the above information indicates that the BPDA/PDA/ODA polyamic acid has been completely transformed to

BPDA/PDA/ODA co-polyimide. Meanwhile, the absorption peak around $1238 \mathrm{~cm}^{-1}$ shown in both spectrums is attributed to the stretching of -C-O-, which confirms the existence of flexible ODA units in the molecular chain [20].

From the 2DWAXD patterns of aligned polyamic acid nanofiber mats (Fig. 4a), a typical pattern for random chain orientation is observed. In contrast, distinct bright diffraction arcs are clearly seen from the pattern of the aligned co-polyimide nanofiber mat in Fig. 4b, revealing preferred crystal orientation along the fiber axis in these materials.

Herman's orientation factor, $\mathrm{f}$, was introduced here to quantify the orientation of crystals before and after imidization and was determined from the fully corrected azimuthal intensity distribution diffracted from the (110) reflection [23] at $\mathrm{d}=3.03 \AA$.

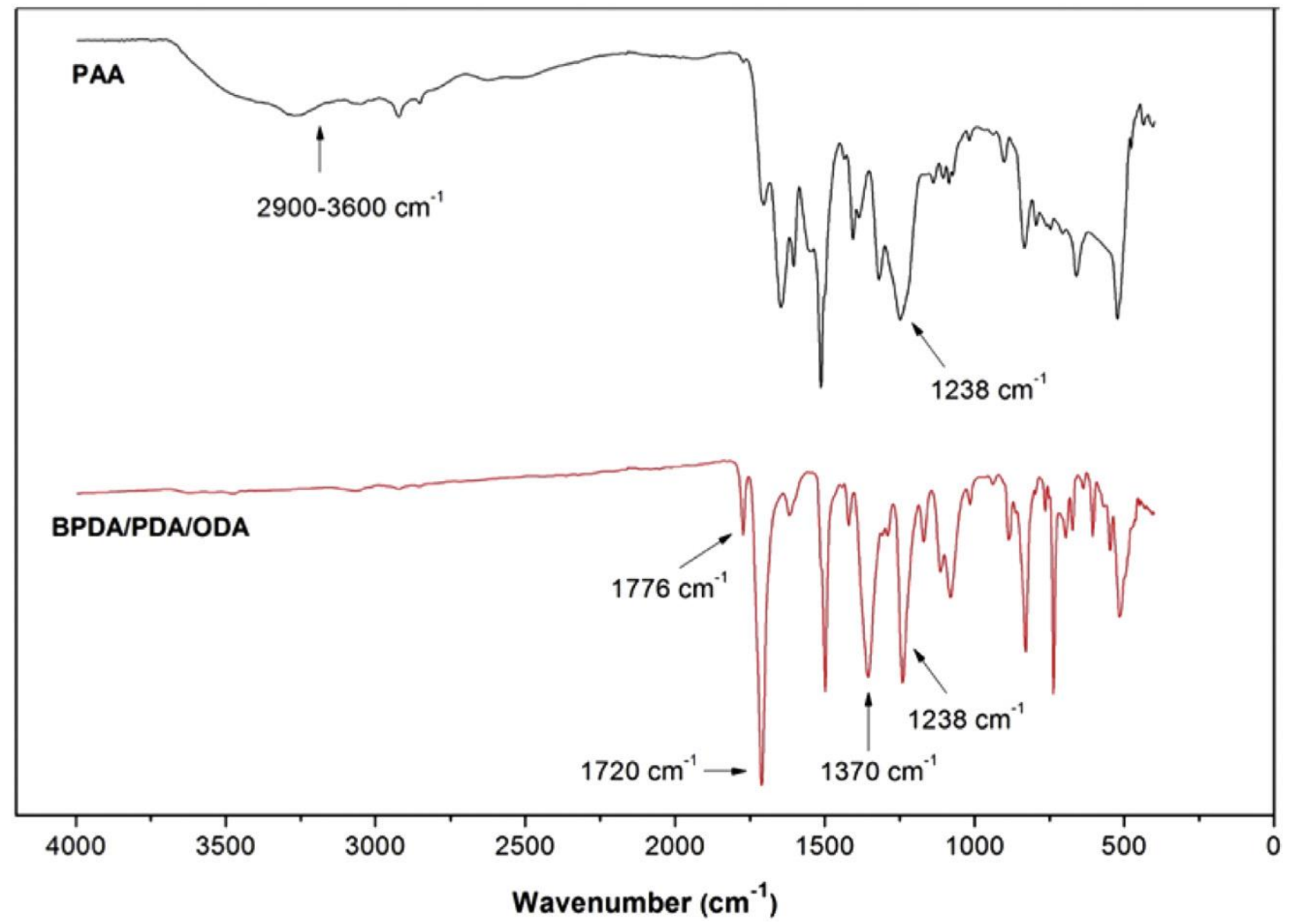

Fig. 3. FTIR spectrum of nanofibers before and after imidization. 
This is the post-print version of the article J. Yao, M.F. Pantano, N.M. Pugno, C.W.M. Bastiaansen, T. Pejis. High-performance electrospun co-polymide nanofibers. Polymer. 76:105-112, 2015.

The Publisher's version is available at http://dx.doi.org/10.1016/j.polymer.2015.08.053

$f=\frac{3<\cos ^{2} \phi>-1}{2}$

$<\cos ^{2} \phi>=\frac{\int_{0}^{\pi / 2} I(\phi) \sin \phi \cos ^{2} \phi d \phi}{\int_{0}^{\pi / 2} I(\phi) \sin \phi d \phi}$

where $\mathrm{I}(\phi)$ is the intensity distribution of the (110) reflection at that angle $\phi$ which is the azimuthal angle between the axis of the crystal plane and the fiber. For a given crystallographic axis, $\left\langle\cos ^{2} \phi\right\rangle$ assumes values of 1 for perfect alignment, 1/3 for random orientations, and 0 for precise perpendicularly, which corresponds to a Herman's orientation factor with respective values of 1,0 and $-1 / 2[21]$.

(a)

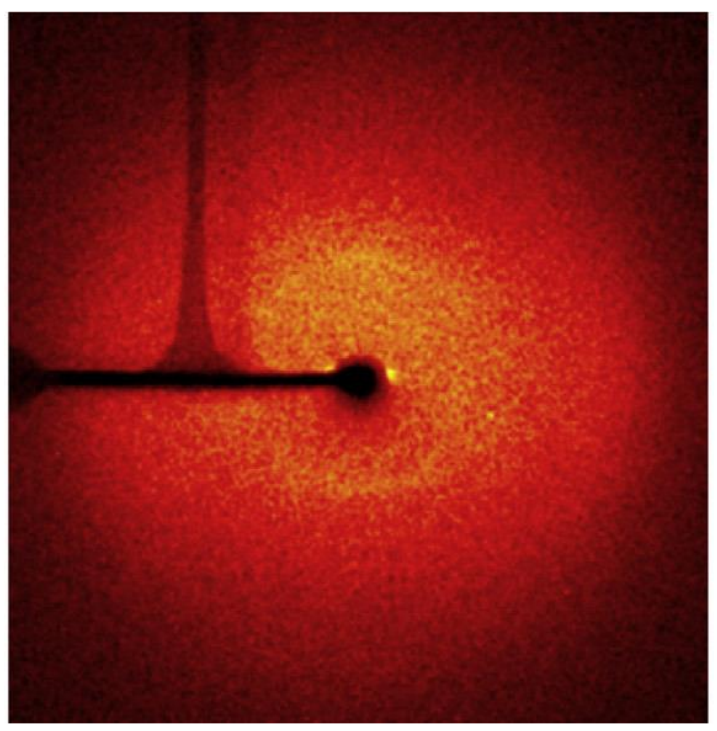

(b)

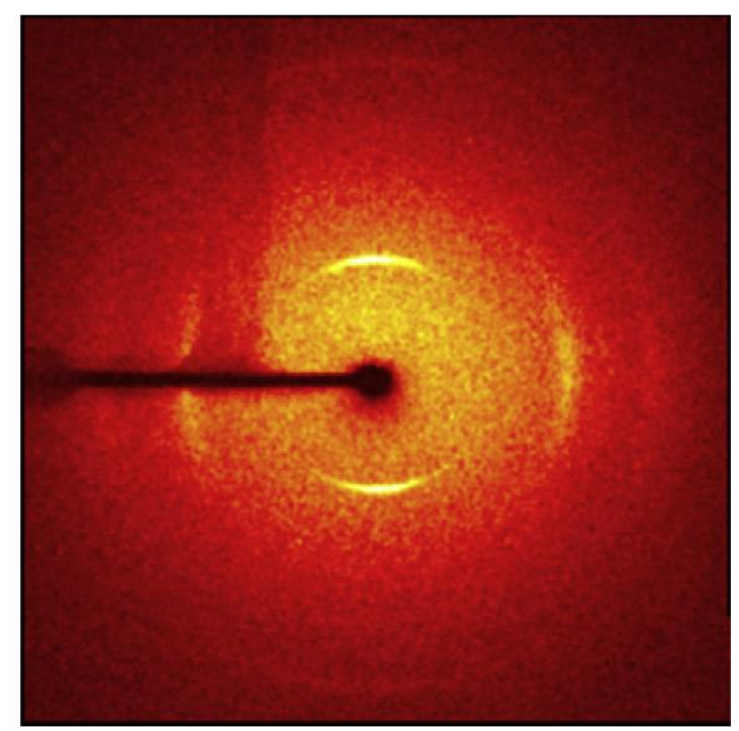

Fig. 4. WAXD patterns of (a) polyamic acid nanofibers before imidization (b) co-polyimide nanofibers after imidization.

In this study, the X-ray intensity as a function of azimuthal angle was plotted in Fig. 5 with a Herman's orientation factor of about 0.12 and 0.7 for BPO nanofibers before and after imidization, respectively. These results confirm that the PAA precursor nanofiber shows low degree of anisotropic behaviour while the imidized BPO nanofiber possesses a high degree of chain orientation.

\subsection{Mechanical properties of co-polyimide nanofibers}

The imidization of polyamic acid is considered to be a molecular chain self-ordering process which is to chemically transform a non-oriented structure into an extended and oriented structure [20,22] by the formation of rigid five-membered imide cycles in the molecular structure upon imidization. This is usually accompanied with increasing mechanical properties of the fiber. It is clearly seen from Fig. 6 that the mechanical properties of the aligned nanofiber mat after imidization improved dramatically when compared to its aligned precursor nanofiber mat. The average Young's modulus increased from $2.5 \mathrm{GPa}$ to $10 \mathrm{GPa}$ whilst the average tensile strength increased from $132 \mathrm{MPa}$ to $1040 \mathrm{MPa}$. 
This is the post-print version of the article J. Yao, M.F. Pantano, N.M. Pugno, C.W.M. Bastiaansen, T. Pejis. High-performance electrospun co-polymide nanofibers. Polymer. 76:105-112, 2015.

The Publisher's version is available at http://dx.doi.org/10.1016/j.polymer.2015.08.053

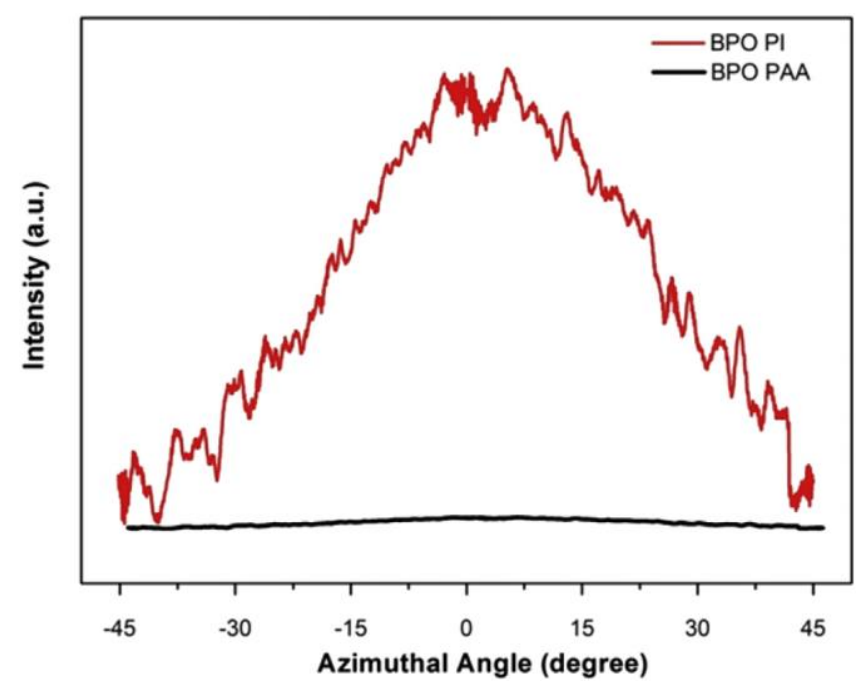

Fig. 5. X-ray intensity versus the azimuth angle for BPO nanofiber mats before (black) and after (red) imidization. (For interpretation of the references to color in this figure legend, the reader is referred to the web version of this article.).

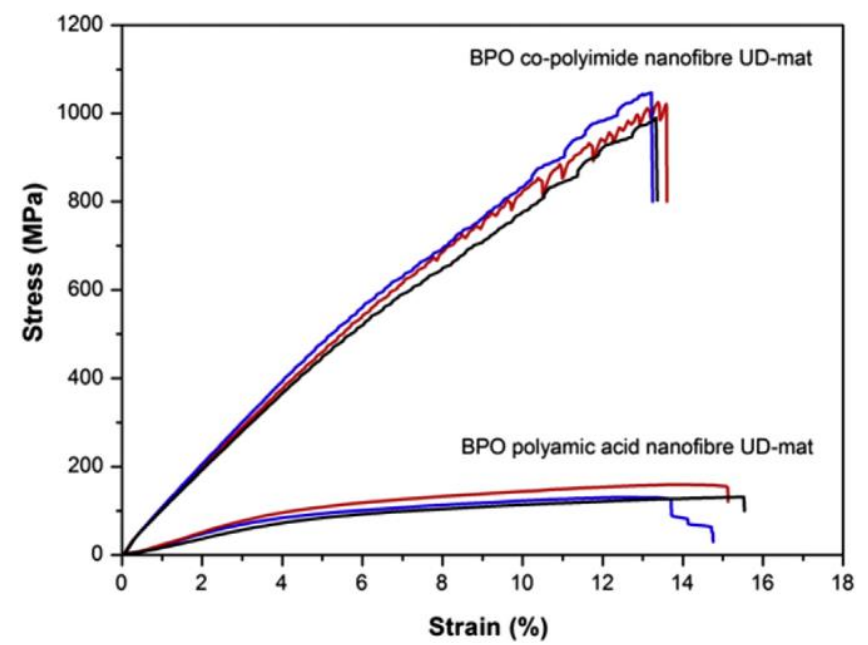

Fig. 6. Stress-strain curves of UD nanofiber mats before and after imidization.

Compared to the reported co-polyimide BPDA/BPA/ODA (BBO) electrospun nanofibers listed in Table 1, these fibers have higher values for Young's modulus and tensile strength, which is important for application in high performance composites.

The mechanical properties also compare very favourable to those of homo-polyimide BPDA/PDA nanofibers. Particularly, the moderate strain-at-break $(\sim 13.5 \%)$ in combination with the higher tensile strength ensures that the BPO co-polyimide nanofiber has a greater toughness than homopolyimide BPDA/PDA nanofibers as listed in Tables 1 and 2. A reasonable explanation for this is that the mole ratio of rigid BPDA/PDA units to flexible BPDA/ODA units in the co-polyimide has a significant influence on the resulting nanofibers. It can be concluded from Chen et al. [20] that with increasing rigid unit content in the co-polyimide, the Young's moduli and strain-at-break of the corresponding nanofibers will increase and decrease, respectively. Meanwhile, the co-polyimide fibers can have a higher tensile strength than homo-polyimide. In our work, the BPO co-polyimide fibers possess an excellent balance of tensile strength and Young's modulus with their tensile strength being much higher than that of homo-polyimide nanofibers [24]. Interestingly, the copolyimide nanofibers reported in this work also exhibit moderate strain-at-break, which in combination with high strength and stiffness, results in a good levels of toughness. 
This is the post-print version of the article J. Yao, M.F. Pantano, N.M. Pugno, C.W.M. Bastiaansen, T. Pejis. High-performance electrospun co-polymide nanofibers. Polymer. 76:105-112, 2015.

The Publisher's version is available at http://dx.doi.org/10.1016/j.polymer.2015.08.053

Table 2. Toughness of the three different types of polyimide nanofibers from Table 1 together with spider silk and Kevlar® 49.

\begin{tabular}{|c|c|c|}
\hline \multirow{2}{*}{$\begin{array}{l}\text { Materials } \\
\text { BPDA/PDA/ODA co-polyimide (this work) }\end{array}$} & & Toughness $\left(\mathrm{MJ} / \mathrm{m}^{3}\right.$ or $\left.\mathrm{MPa}\right)$ \\
\hline & $\begin{array}{lr}\text { Nonwoven } & \text { UD } \\
\text { nanofiber } & \text { mat } \\
\text { Multifilament bundle }\end{array}$ & $\begin{array}{l}77 \pm 3 \\
39 \pm 4\end{array}$ \\
\hline BPDA/PDA polyimide & $\begin{array}{l}\text { Nonwoven } \\
\text { nanofiber mat } \\
\text { Single nanofiber }\end{array}$ & $\begin{array}{l}\sim 20[23] \\
\sim 22[23]\end{array}$ \\
\hline BPDA/BPA/ODA co-polyimide & $\begin{array}{ll}\begin{array}{l}\text { Nonwoven } \\
\text { nanofiber mat }\end{array} & \text { UD }\end{array}$ & $\sim 120[20]$ \\
\hline Spider silk & Single nanofiber & $\begin{array}{l}160 \text { (MA silk) [26] } \\
150 \text { (Viscid silk) [26] } \\
221 \text { (Nephila edulis silk) [27] }\end{array}$ \\
\hline Kevlar® 49 & Single nanofiber & $50[26]$ \\
\hline
\end{tabular}

The toughness of spider silk and Kevlar® 49 are listed in Table 2 for comparison. The toughness of our high performance BPO nanofibers approaches Kevlar® 49 fiber, which is commonly used for anti-ballistic applications [25]. Although the BPO nanofibers have lower toughness than spider silk they have favourable levels of strength and stiffness, properties required for advanced composite applications.

It is important to note that the toughness of UD mats is not the same as that of individual fibers. Provided the fact that the toughness of UD mats is calculated from the enclosed area under the stress-strain curve, strain-at-break significantly influences the resulting toughness. In the case of electrospun non-woven mats the random orientation of the nanofibers or fiber entanglements in these mats can lead to extensive nanofiber sliding and deformation during tensile testing. Hence, there is little correlation between the toughness of individual nanofibers and random non-woven nanofiber mats, while the toughness of UD mats represents better the intrinsic toughness of individual fibers.

It should be noted that even in the case of electrospun aligned mats discrepancies exist between the mechanical properties of UD mats and those of single nanofibers. In most aligned electrospun mats some level of misalignment exist in these mats and because of this misalignment these mats typically have inferior mechanical properties compared to single electrospun fibers. For the tensile testing of individual electrospun nanofibers two main techniques have been reported. The first one involves in-situ tensile testing using atomic force microscopy (AFM) for force measurement and SEM for imaging. Typical stressestrain behaviour can be obtained by this method on single nanofibers [28]. Mechanical properties of electrospun poly(vinyl alcohol) (PVA), polyamide 6 and mineralized collagen fibrils have been successfully tested via this technique. A second method involved the use of a high resolution nano-tensile tester that allows for the testing of single nanofibers. This method has been used by Tan et al., Leong et al. and Chen et al. [23,29,30].

For the testing of single nanofibers two main challenges have to be faced. The first one involves the separation of single nanofibers from aligned mats and the other one is manipulating and transporting single nanofibers to the tensile tester. In both cases, the single nanofiber can easily be damaged. A relatively convenient alternative method to evaluate the mechanical property of nanofibers is to test aligned multifilament bundles. Compared to aligned nanofiber mats, such bundles have fewer fibers and have nearly perfect fiber alignment so that they reflect better the intrinsic mechanical properties of corresponding single nanofibers.

Before tensile testing, these multifilament nanofiber bundles were mounted on a paper frame using double-sided sticky tapes and epoxy glue as shown in Fig. 7a. Fig. $7 \mathrm{~b}$ shows a nanofiber bundle before tensile testing and Fig. 7c presents a nanofiber bundle including 29 filaments after testing. 
This is the post-print version of the article J. Yao, M.F. Pantano, N.M. Pugno, C.W.M. Bastiaansen, T. Pejis. High-performance electrospun co-polymide nanofibers. Polymer. 76:105-112, 2015.

The Publisher's version is available at http://dx.doi.org/10.1016/j.polymer.2015.08.053

Once the specimen is prepared, it needs to be gripped between two clamps to ensure the gauge length is equal to the inner length $(10 \mathrm{~mm})$ of the paper frame. In this work, we used a high resolution $(50 \mathrm{nN})$ universal micro-tensile testing machine (Agilent T150) [31]. The cross-sectional area of the multifilament bundle is determined by counting the number of filaments and then multiplying this by the cross-sectional area of the individual nanofibers. Here, $275 \mathrm{~nm}$ is considered as the average filament diameter as detected by SEM taking into account the $\sim 5 \mathrm{~nm}$ thickness of the gold coating. It is worth mentioning that the number of filaments in a bundle is determined from the number of broken fiber ends in a bundle (Fig. 7c) rather than from the multifilament bundle before testing (Fig. 7b) in case any broken fiber ends exists in the bundle before testing. The Young's modulus and tensile strength of the aligned copolyimide nanofiber bundles are found to be $38 \pm 2$ GPa and $1550 \pm 70 \mathrm{MPa}$, respectively (Fig. 8). The relatively high mechanical properties of these bundles in comparison to the UD mats are the result of a better alignment of individual nanofibers in the bundles compared to the mats.

In order to estimate single nanofiber properties from the bundle data we applied Daniel's bundle theory based on Weibull statistics, which was recently extended for considering hierarchical [32], composite [33] and even self-healing materials [34].

Accordingly, describing the nanofiber strength statistics with the classical Weibull statistics, having unknown mean strength $\sigma_{\mathrm{f}}$ and Weibull modulus $\mathrm{m}$, we deduce:

$$
\begin{aligned}
& m=\frac{1}{\ln \left(1+\frac{\theta_{b}^{2}}{\sigma_{b}^{2}} N\right)} \\
& \sigma_{f}=\sigma_{b} m^{1 / m} e^{1 / m} \Gamma\left(1+\frac{1}{m}\right)
\end{aligned}
$$

where $\sigma_{\mathrm{b}}, \theta_{\mathrm{b}}, \mathrm{N}$ are respectively the bundle mean strength, standard deviation and number of nanofibers in the bundle ( $\Gamma$ is the gamma function).

Since the tensile strength of the aligned co-polyimide nanofiber bundles composed of $N=30$ (average of 28, 29 and 33 from three bundles) individual nanofibers was measured at $1550 \pm 70$ $\mathrm{MPa}$, we can now use Equation (4) to estimate $\mathrm{m}=16.8$, while single fiber strength can be calculated from Equation (5) $\sigma_{\mathrm{f}}=1.9 \mathrm{GPa}$. Note that although the experimental estimation of $\theta_{\mathrm{b}}$ could be not very accurate due to the relative small number of tests $(n=3)$, the Weibull modulus of 16.8 is in agreement with Weibull moduli reported for polymeric fibers. Weibull moduli for polymeric fibers were found to be in the range of $8 \mathrm{e} 18$ [35], which in turn confirms the reliability of $\mathrm{wb}$ and thus the reliability of the predicted single BPO nanofiber strength data.

Fiber strengths approaching $2 \mathrm{GPa}$ show that the current electrospun BPO nanofibers are truly high performance fibers, with strength values that are among the highest ever reported for electrospun fibers (further investigation shows the Young's modulus of this BPO nanofibers is approximately 59 $\mathrm{GPa}[36])$. It shows the potential of electrospinning soluble flexible chain polyimide precursors and subsequently converting these into chain extended structures through chemistry rather than solidstate drawing. 
This is the post-print version of the article J. Yao, M.F. Pantano, N.M. Pugno, C.W.M. Bastiaansen, T. Pejis. High-performance electrospun co-polymide nanofibers. Polymer. 76:105-112, 2015.

The Publisher's version is available at http://dx.doi.org/10.1016/j.polymer.2015.08.053

(a)

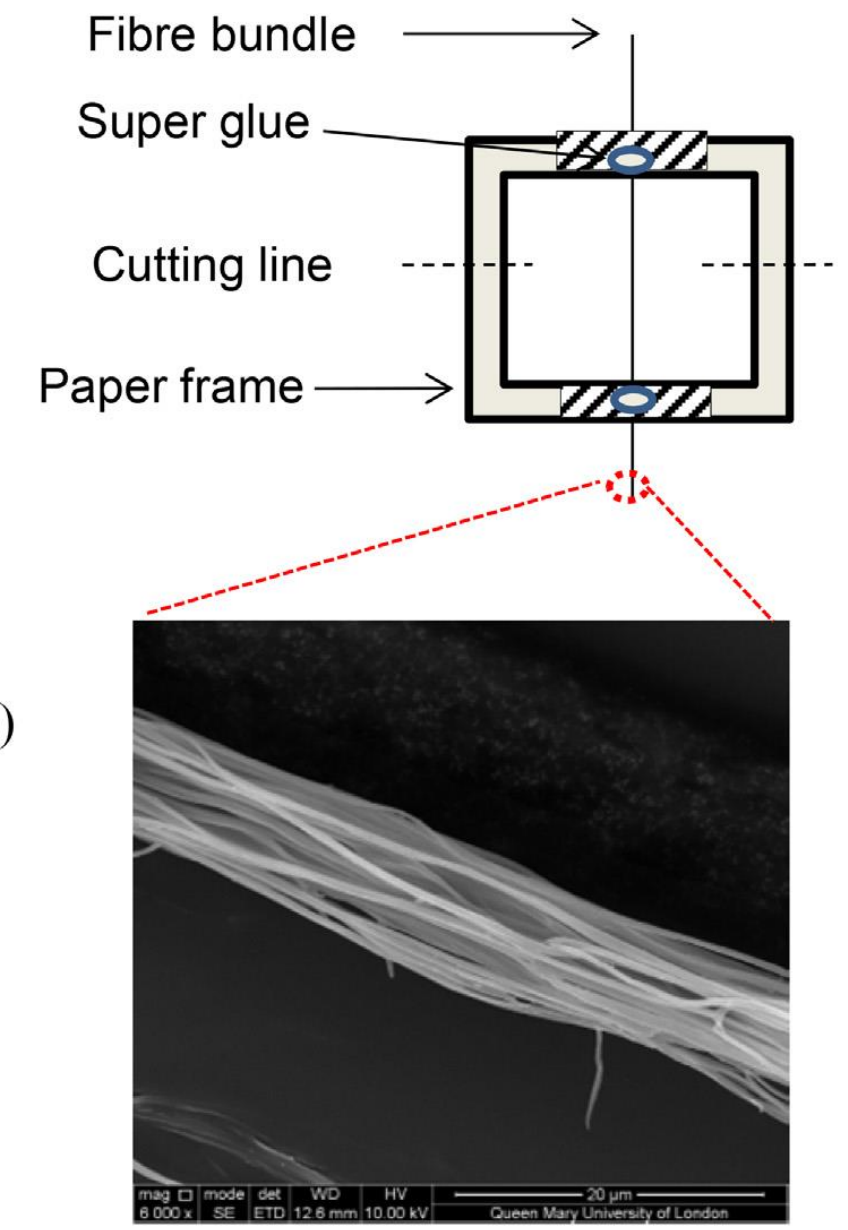

(c)

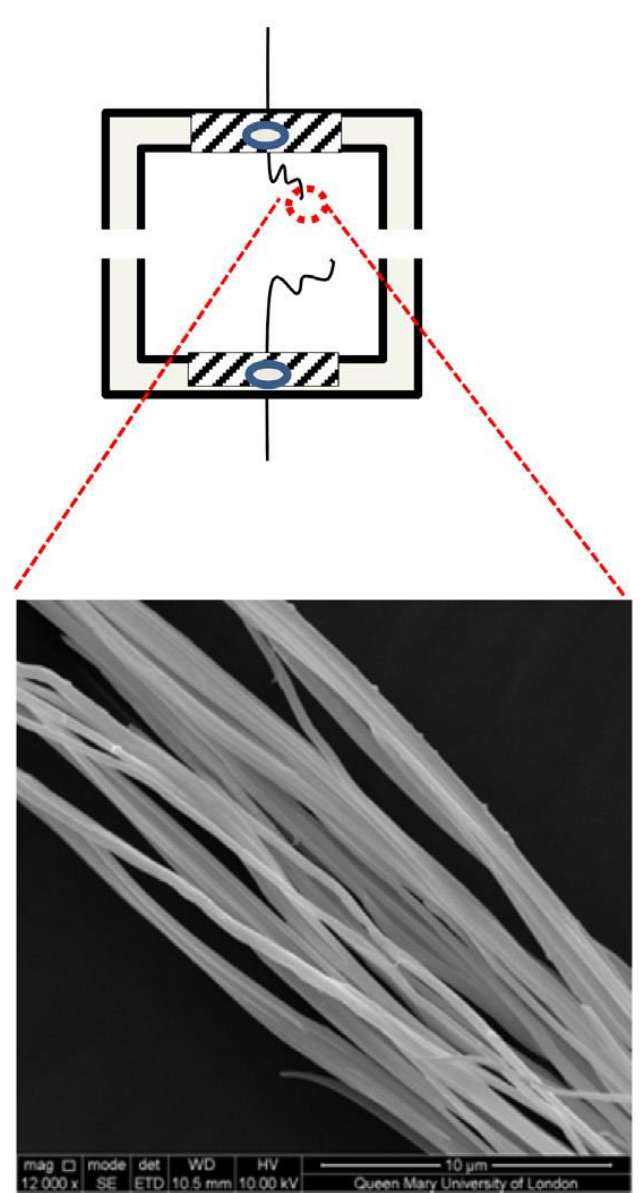

Fig. 7. (a) Schematic illustration of bundle sample preparation for mechanical testing and SEM micrographs of a multifilament nanofiber bundle of 29 filaments (b) before testing and (c) after testing.

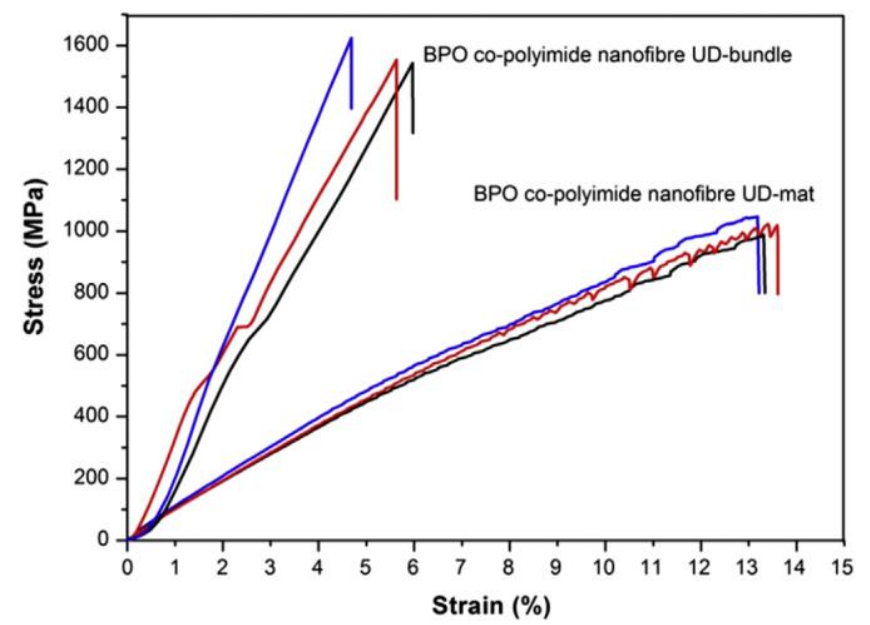

Fig. 8. Stress-strain curves of UD nanofiber mats and bundles.

\section{Conclusions}

In this work, BPO co-polyimide precursor polyamic acid (PAA) was first synthesized and electrospun into nanofibers and then imidized to high strength and high modulus co-polyimide nanofibers. Aligned co-polyimide nanofiber mats possessed a mean Young's modulus, strength and strain-at-break of respective $10 \mathrm{GPa}, 1.04 \mathrm{GPa}$, and 13.5\%. In comparison with reported copolyimide nanofibers (BBO) of similar chemical structure, these BPO copolyimide nanofibers were 
This is the post-print version of the article J. Yao, M.F. Pantano, N.M. Pugno, C.W.M. Bastiaansen, T. Pejis. High-performance electrospun co-polymide nanofibers. Polymer. 76:105-112, 2015.

The Publisher's version is available at http://dx.doi.org/10.1016/j.polymer.2015.08.053

both strong and stiff, while at the same time exhibiting high levels of toughness. Because of their relatively high strain-at-break these BPO co-polyimide nanofibers exhibit greater toughness than homo-polyimide (BPDA/PDA) nanofibers with comparable toughness to Kevlar® 49.

Mechanical properties of multifilament nanofiber bundles ( $\sim 30$ filaments) were tested by virtue of a micro-tensile tester. Young's moduli of $38 \pm 2 \mathrm{GPa}$ and tensile strengths of $1550 \pm 70 \mathrm{MPa}$ were found. Further analysis of this bundle data using of Daniel's fiber bundle theory based on Weibull statistics lead to a predicted tensile strength for single co-polyimide nanofibers of around 1.9 GPa. The high performance co-polyimide electrospun fibers reported here are among the strongest ever reported and are expected to make interesting nano-reinforcements for composites and this will be the focus of our future work.

\section{References}

[1] J. Doshi, D.H. Reneker, J. Electrost. 35 (2) (1995) 151-160.

[2] A. Greiner, J.H. Wendorff, Angew. Chem. Int. Ed. 46 (30) (2007) 5670-5703.

[3] D. Li, Y. Xia, Adv. Mater. 16 (14) (2004) 1151-1170.

[4] A. Greiner, J. Wendorff, Functional self-assembled nanofibers by electrospinning, in: Selfassembled Nanomaterials I, Springer Berlin Heidelberg, Berlin, Germany, 2008, pp. 107-171.

[5] J. Yao, C.W.M. Bastiaansen, T. Peijs, Fibers 2 (2) (2014) 158-186.

[6] L.M. Hansen, D.J. Smith, D.H. Reneker, W. Kataphinan, J. Appl. Polym. Sci. 95 (2) (2005) 427-434.

[7] Z.-M. Huang, Y. Zhang, S. Ramakrishna, C. Lim, Polymer 45 (15) (2004) 5361-5368.

[8] K. Lee, H. Kim, M. Khil, Y. Ra, D. Lee, Polymer 44 (4) (2003) 1287-1294.

[9] M. Richard-Lacroix, C. Pellerin, Macromolecules 46 (24) (2013) 9473-9493.

[10] C. Huang, S. Chen, D.H. Reneker, C. Lai, H. Hou, Adv. Mater. 18 (5) (2006) 668-671.

[11] X. Zong, S. Ran, D. Fang, B.S. Hsiao, B. Chu, Polymer 44 (17) (2003) 4959-4967.

[12] S.Z. Wu, X.P. Yang, F. Zhang, X.X. Hou, Adv. Mater. Res. 47 (2008) 1169-1172.

[13] A. Arinstein, E. Zussman, J. Polym. Sci. Part B Polym. Phys. 49 (10) (2011) 691-707.

[14] M. Naraghi, S. Arshad, I. Chasiotis, Polymer 52 (7) (2011) 1612-1618.

[15] C.-L. Pai, M.C. Boyce, G.C. Rutledge, Polymer 52 (10) (2011) 2295-2301.

[16] S. Kwolek, P. Morgan, J. Schaefgen, L. Gulrich, Macromolecules 10 (6) (1977) 1390-1396.

[17] T. Bair, P. Morgan, F. Killian, Macromolecules 10 (6) (1977) 1396e1400.

[18] M. Dobb, D. Johnson, B. Saville, J. Polym. Sci. Polym. Phys. Ed. 15 (12) (1977) 2201-2211.

[19] J. Yao, J. Jin, E. Lepore, N.M. Pugno, C.W.M. Bastiaansen, T. Peijs, Macromol. Mater. Eng. (2015), http://dx.doi.org/10.1002/mame.201500130.

[20] S. Chen, P. Hu, A. Greiner, C. Cheng, H. Cheng, F. Chen, H. Hou, Nanotechnology 19 (1) (2008) 015604.

[21] T. Kongkhlang, K. Tashiro, M. Kotaki, S. Chirachanchai, J. Am. Chem. Soc. 130 (46) (2008) 15460-15466.

[22] A.V. Goponenko, H. Hou, Y.A. Dzenis, Polymer 52 (17) (2011) 3776-3782.

[23] F. Chen, X. Peng, T. Li, S. Chen, X.-F. Wu, D.H. Reneker, H. Hou, J. Phys. D Appl. Phys. 41 (2) (2008) 025308.

[24] T. Sukhanova, Y.G. Baklagina, V. Kudryavtsev, T. Maricheva, F. Lednický, Polymer 40 (23) (1999) 6265-6276.

[25] J.M. Zhang, Z. Mousavi, N. Soykeabkaew, P. Smith, T. Nishino, T. Peijs, ACS Appl. Mater. Interfaces 2 (3) (2010) 919-926.

[26] D.A. Tirrell, Science 271 (5245) (1996) 39-40.

[27] F. Vollrath, D.P. Knight, Nature 410 (6828) (2001) 541-548.

[28] F. Hang, D. Lu, R.J. Bailey, I. Jimenez-Palomar, U. Stachewicz, B. Cortes-Ballesteros, M.

Davies, M. Zech, C. B€odefeld, A.H. Barber, Nanotechnology 22 (36) (2011) 365708. 
This is the post-print version of the article J. Yao, M.F. Pantano, N.M. Pugno, C.W.M. Bastiaansen, T. Pejis. High-performance electrospun co-polymide nanofibers. Polymer. 76:105-112, 2015.

The Publisher's version is available at http://dx.doi.org/10.1016/j.polymer.2015.08.053

[29] E. Tan, C. Lim, Appl. Phys. Lett. 84 (9) (2004) 1603-1605.

[30] S.Y. Chew, T.C. Hufnagel, C.T. Lim, K.W. Leong, Nanotechnology 17 (15) (2006) 3880.

[31] E. Lepore, A. Marchioro, M. Isaia, M.J. Buehler, N.M. Pugno, PloS One 7 (2) (2012) e30500.

[32] N.M. Pugno, F. Bosia, T. Abdalrahman, Phys. Rev. E 85 (1) (2012) 011903.

[33] N.M. Pugno, T. Abdalrahman, Compos. Part B Eng. 45 (1) (2013) 303-307.

[34] F. Bosia, T. Abdalrahman, N.M. Pugno, Nanoscale 4 (4) (2012) 1200-1207.

[35] F. Bosia, T. Abdalrahman, N.M. Pugno, Langmuir 30 (4) (2014) 1123-1133.

[36] J. Yao, High Strength and High Modulus Electrospun Nanofibres (Ph.D. thesis), Queen Mary University of London, 2014. 